Article

\title{
Three New Abietane-Type Diterpenoids from Callicarpa macrophylla Vahl.
}

\author{
Zhen-Hui Wang *, Chao Niu, De-Jun Zhou, Ji-Chuan Kong and Wen-Kui Zhang
}

College of Medicine, Henan Polytechnic University, Jiaozuo 454000, China; rendyx@163.com (C.N.); zhoudj@hpu.edu.cn (D.-J.Z.); kongjichuan@126.com (J.-C.K.); z404105311@me.com (W.-K.Z.)

* Correspondence: wangzhenhui1984@163.com; Tel.: +86-391-398-6840; Fax: +86-391-398-6831

Academic Editor: Derek J. McPhee

Received: 20 March 2017; Accepted: 13 May 2017; Published: 19 May 2017

\begin{abstract}
Three new abietane-type diterpenoids, named callicapoic acid M3 (1), callicapoic acid M4 (2) and callicapoic acid M5 (3), were isolated from the Callicarpa macrophylla Vahl. Their structures were established by spectroscopic techniques (IR, UV, MS, 1D and 2D NMR). All the isolated three compounds were evaluated for inhibitory activity on NO production in LPS-activated RAW 264.7 macrophage cells by using MTT assays. Compounds 1, 2 and 3 showed potent inhibitory activity, with inhibition rates of $34.47-40.13 \%$.
\end{abstract}

Keywords: Callicarpa macrophylla Vahl.; abietane-type diterpenoids; NMR; anti-inflammatory activity

\section{Introduction}

The genus Callicarpa belongs to the family Verbenaceae, with about 190 species widely distributed throughout the tropical and subtropical regions of Asia and Oceanica and parts of America [1,2]. Many Callicarpa species are used in Chinese folk medicine for various indications [2]. Compounds that represent a variety of different classes have been reported, including diterpenoids, triterpenoids, flavonoids, phenolic acids, volatile oils and so on [2-5]. Currently, Callicarpa macrophylla Vahl. is used as a folk medicine in China's Yunnan Province, were the root, the stem, and the leaves are all used in medicine. Callicarpa macrophylla Vahl. has a bitter taste, slightly acrid and flat, with clinical actions that eliminate stasis to activate blood circulation and stop bleeding, and it also has detumescence and analgesic actions [6].
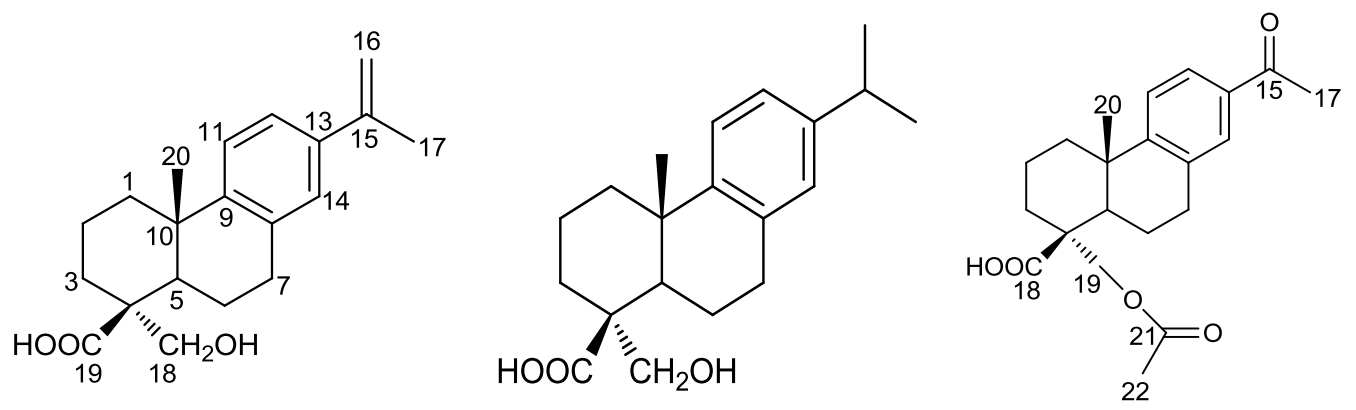

Figure 1. The structures of compounds 1 to 3.

Past phytochemical studies on Callicarpa macrophylla Vahl. Have revealed the presence of pentacyclic triterpenes, sterols [6], and diterpenes [7,8]. Additionally, some of the literature has reported that diterpenoid compounds in Callicarpa showed potent anti-inflammatory activities $[9,10]$. Being interested in finding more biologically active substances from this folk medicine, we further 
undertook an investigation to explore its phytochemical composition. As a result, three new abietane-type diterpenoids 1-3, named callicapoic acids M 3-5 (Figure 1) were isolated from the dried whole herb of Callicarpa macrophylla Vahl. This paper deals with their structural elucidation and anti-inflammatory activity against RAW 264.7 macrophage cells line determined by means of MTT assays.

\section{Results and Discussion}

Compound 1 (callicapoic acid M3), obtained as white amorphous powder (from acetone), gave the molecular formula $\mathrm{C}_{20} \mathrm{H}_{26} \mathrm{O}_{3}$, as deduced from the HR-ESI-MS peak at $m / z 315.1958[\mathrm{M}+\mathrm{H}]^{+}$. Its IR spectrum showed hydroxyl $\left(3401 \mathrm{~cm}^{-1}\right)$ and carboxyl group $\left(1700 \mathrm{~cm}^{-1}\right)$ absorptions, and the UV spectrum showed the presence of an aromatic moiety with maxima at 211 and $250 \mathrm{~nm}$. The ${ }^{1} \mathrm{H}-\mathrm{NMR}$ spectrum of $\mathbf{1}$ (Table 1) revealed an isopropenyl group $\left[\delta_{\mathrm{H}} 2.11(3 \mathrm{H}, \mathrm{s}), 5.02(1 \mathrm{H}, \mathrm{s}), 5.32\right.$ $(1 \mathrm{H}, \mathrm{s})]$, one methyl group $\left[\delta_{\mathrm{H}} 1.16(3 \mathrm{H}, \mathrm{s})\right]$, a pair of methylene protons $\left[\delta_{\mathrm{H}} 3.48,4.16\right.$ (each $1 \mathrm{H}, \mathrm{d}$, $J=5.9 \mathrm{~Hz}$ )] bearing an oxygen function, and a 1,2,4 substitution pattern for the aromatic $\mathrm{C}$ ring was easily recognized from inspection of other ${ }^{1} \mathrm{H}-\mathrm{NMR}$ signals $\left[\delta_{\mathrm{H}} 7.21,8.25\right.$ (each $1 \mathrm{H}, \mathrm{d}, J=8.2 \mathrm{~Hz}$ ) and $7.12(1 \mathrm{H}, \mathrm{s})]$ and of other $\mathrm{C}$ ring aromatized compounds [11-13].

The ${ }^{13} \mathrm{C}$-NMR spectrum of $\mathbf{1}$ (Table 1 ) confirmed the presence of a benzene ring, in addition to two methyl, six methylene, one methine, one carboxyl, two olefinic carbon signals, and two quaternary carbon signals, as well as an additional methylene carbon $\left(\delta_{C} 71.4\right)$ attached to an oxygen function. From this information, compound $\mathbf{1}$ was inferred to be an abietane-type diterpene by comparison with the literature identification data of similar typical abietanes, like the triptobenzenes A-K isolated from T. wilfordiivar. Regelii [14] and T. hypoglaucum [15].

In the HMBC spectrum of 1 (Figure 2), the methyl proton signal $\left(\delta_{\mathrm{H}} 2.11\right)$ of the isopropenyl group correlated with the carbon signals at $\delta_{C} 138.3$ (C-13), $142.9(\mathrm{C}-15)$, and $111.7(\mathrm{C}-16)$, and the proton signal $\delta_{\mathrm{H}} 8.25(\mathrm{H}-12)$ correlated with signals at $\delta_{\mathrm{C}} 142.9$ (C-15), $147.2(\mathrm{C}-9)$, and $126.0(\mathrm{C}-14)$. In turn, the proton signal $\delta_{\mathrm{H}} 7.12(\mathrm{H}-14)$ correlated with the signals at $\delta_{\mathrm{C}} 142.9$ (C-15), $147.2(\mathrm{C}-9), 123.1$ (C-12), and 31.6 (C-7). From these observations, the location of the isopropenyl group at C-13 was inferred. Further, the proton signals at $\delta_{\mathrm{H}} 3.48,4.16\left(\mathrm{H}_{2}-18\right)$ correlated with the signals at $\delta_{\mathrm{C}} 32.0(\mathrm{C}-3)$, 49.9 (C-4), 47.7 (C-5), and 181.1 (C-19), implied the hydroxyl group in 1 could be assigned to position C-18. In the NOESY spectrum, the proton signals at $\delta_{\mathrm{H}} 3.48,4.16\left(\mathrm{H}_{2}-18\right)$ showed correlations with the proton signal at $\delta_{\mathrm{H}} 1.69(\mathrm{H}-5)$, and showed no correlation with the methyl proton signals at $\delta_{\mathrm{H}}$ $1.16\left(\mathrm{H}_{3}-20\right)$. Thus, the configuration of the hydroxy methylene at $\mathrm{C}-4$ was confirmed to be $\alpha$, and the methyl at $\mathrm{C}-10$ was confirmed to be $\beta$. The above evidence allowed identification of compound 1 as 18-hydroxy-8,11,13,15-abietatetraen-19-oic acid.

Callicapoic acid M4 (2) was isolated as a white amorphous powder (from acetone). Its molecular formula was established as $\mathrm{C}_{20} \mathrm{H}_{28} \mathrm{O}_{3}$ by the HR-ESI-MS signal at $m / z 339.1927[\mathrm{M}+\mathrm{Na}]^{+}$. The 1D (Table 1) and 2D NMR data of 2 showed the presence of an abietane-type diterpene skeleton, which indicated its structure be similar to that of $\mathbf{1}$, except for a side chain isopropyl group, suggested by the appearance of characteristic resonances at $\delta_{\mathrm{H}} 1.21(3 \mathrm{H}, \mathrm{s}), 1.22(3 \mathrm{H}, \mathrm{s})$, and $2.82(1 \mathrm{H}, \mathrm{m})$; and $\delta_{\mathrm{C}} 24.0,24.0$ and 33.4. In the HMBC spectrum (Figure 2), the methine proton signal $\left(\delta_{\mathrm{H}} 2.82\right)$ of the isopropyl group correlated with C-12 $(\delta 124.1), C-13(\delta 145.8)$ and C-14 $(\delta 126.8)$. In turn, the proton signals at $\delta_{\mathrm{H}} 6.99$ $(\mathrm{H}-12)$ and $6.87(\mathrm{H}-14)$ correlated with the methine signal at $\delta_{\mathrm{C}} 33.4$ (C-15). From these observations, the location of the side chain of isopropyl group at $\mathrm{C}-13$ was inferred. The relative configuration of 2 was established by a NOESY experiment, and $4-\mathrm{CH}_{2} \mathrm{OH}, 10-\mathrm{CH}_{3}$ were found to be the same as those of 1. Accordingly, compound 2 was identified as 18-hydroxy-8,11,13-abietatetraen-19-oic acid (Figure 1) and named callicapoic acid M4 (2). Compound 2 is the C-4 epimer of a known compound described in the literature [16]. 
Table 1. ${ }^{1} \mathrm{H}-\left(600 \mathrm{MH}_{\mathrm{Z}}\right)$ and ${ }^{13} \mathrm{C}-\mathrm{NMR}\left(150 \mathrm{MH}_{\mathrm{Z}}\right)$ data of compounds 1-3 $\left(\mathrm{CDCl}_{3}\right)$.

\begin{tabular}{|c|c|c|c|c|c|c|}
\hline \multirow{2}{*}{ No. } & \multicolumn{2}{|l|}{1} & \multicolumn{2}{|l|}{2} & \multicolumn{2}{|l|}{3} \\
\hline & ${ }^{1} \mathbf{H}$ & ${ }^{13} \mathrm{C}$ & ${ }^{1} \mathbf{H}$ & ${ }^{13} \mathrm{C}$ & ${ }^{1} \mathbf{H}$ & ${ }^{13} \mathrm{C}$ \\
\hline $1 \alpha$ & $1.37(\mathrm{~m})$ & 38.9 & $1.38(\mathrm{t}, 12.8)$ & 38.9 & $\begin{array}{c}1.39 \text { (ddd, 3.5, 9.9 } \\
13.5)\end{array}$ & 38.6 \\
\hline $1 \beta$ & $2.30(\mathrm{~m})$ & & $2.28(\mathrm{~d}, 12.8)$ & & $2.33(\mathrm{~d}, 13.5)$ & \\
\hline $2 \alpha$ & $1.70(\mathrm{~m})$ & 19.3 & $1.69(\mathrm{~d}, 11.7)$ & 19.3 & $1.73(\mathrm{~m})$ & 19.2 \\
\hline $2 \beta$ & $2.06(\mathrm{~m})$ & & $2.05(\mathrm{~m})$ & & $2.12(\mathrm{~m})$ & \\
\hline $3 \alpha$ & $1.13(\mathrm{~m})$ & 32.0 & $1.12(\mathrm{~m})$ & 32.0 & $1.19(\mathrm{dd}, 4.6,13.5)$ & 32.0 \\
\hline $3 \beta$ & $2.45(\mathrm{~d}, 9.3)$ & & $2.45(\mathrm{~d}, 11.7)$ & & $2.40(\mathrm{~d}, 13.5)$ & \\
\hline 4 & & 49.9 & & 49.9 & & 47.9 \\
\hline 5 & $1.69(\mathrm{~m})$ & 47.7 & $1.69(\mathrm{~d}, 11.9)$ & 47.7 & $1.78(\mathrm{~d}, 12.3)$ & 47.6 \\
\hline $6 \alpha$ & $2.02(\mathrm{~m})$ & 20.8 & $2.02(\mathrm{~m})$ & 20.8 & $2.03(\mathrm{dd}, 5.4,13.5)$ & 20.8 \\
\hline $6 \beta$ & $2.10(\mathrm{~m})$ & & $2.08(\mathrm{~m})$ & & $2.15(\mathrm{~m})$ & \\
\hline $7 \alpha$ & $2.80(\mathrm{~m})$ & 31.6 & $2.78(\mathrm{~m})$ & 31.5 & $2.84(\mathrm{~m})$ & 31.5 \\
\hline $7 \beta$ & $2.87(\mathrm{~m})$ & & $2.85(\mathrm{~m})$ & & $2.97(\mathrm{dd}, 4.7,16.8)$ & \\
\hline 8 & & 134.7 & & 134.7 & & 135.4 \\
\hline 9 & & 147.2 & & 145.3 & & 153.3 \\
\hline 10 & & 38.2 & & 38.1 & & 39.0 \\
\hline 11 & $7.21(\mathrm{~d}, 8.2)$ & 125.3 & $7.17(\mathrm{~d}, 8.3)$ & 125.3 & $7.35(\mathrm{~d}, 8.5)$ & 125.9 \\
\hline 12 & $8.25(\mathrm{~d}, 8.2)$ & 123.1 & $6.99(\mathrm{~d}, 8.3)$ & 124.1 & $7.71(\mathrm{dd}, 1.5,8.5)$ & 126.0 \\
\hline 13 & & 138.3 & & 145.8 & & 134.8 \\
\hline 14 & $7.12(\mathrm{~s})$ & 126.0 & $6.87(\mathrm{~s})$ & 126.8 & $7.65(\mathrm{~d}, 1.5)$ & 129.5 \\
\hline 15 & & 142.9 & $2.82(\mathrm{~m})$ & 33.4 & & 198.3 \\
\hline $16 a$ & $5.02(\mathrm{~s})$ & 111.7 & $1.21(\mathrm{~s})$ & 24.0 & & \\
\hline $16 b$ & $5.32(\mathrm{~s})$ & & & & & \\
\hline 17 & $2.11(\mathrm{~s})$ & 21.7 & $1.22(\mathrm{~s})$ & 24.0 & $2.56(\mathrm{~s})$ & 26.7 \\
\hline $18 a$ & $3.48(\mathrm{~d}, 5.9)$ & 71.4 & $3.48(\mathrm{~d}, 9.4)$ & 71.5 & $4.10(\mathrm{~d}, 10.4)$ & 71.6 \\
\hline $18 b$ & $4.16(\mathrm{~d}, 5.9)$ & & $4.16(\mathrm{~d}, 9.4)$ & & $4.49(\mathrm{~d}, 10.4)$ & \\
\hline 19 & & 181.1 & & 181.1 & & 180.3 \\
\hline 20 & $1.16(\mathrm{~s})$ & 23.4 & $1.15(\mathrm{~s})$ & 23.5 & $1.17(\mathrm{~s})$ & 23.1 \\
\hline 21 & & & & & & 171.0 \\
\hline 22 & & & & & $2.06(\mathrm{~s})$ & 20.9 \\
\hline
\end{tabular}

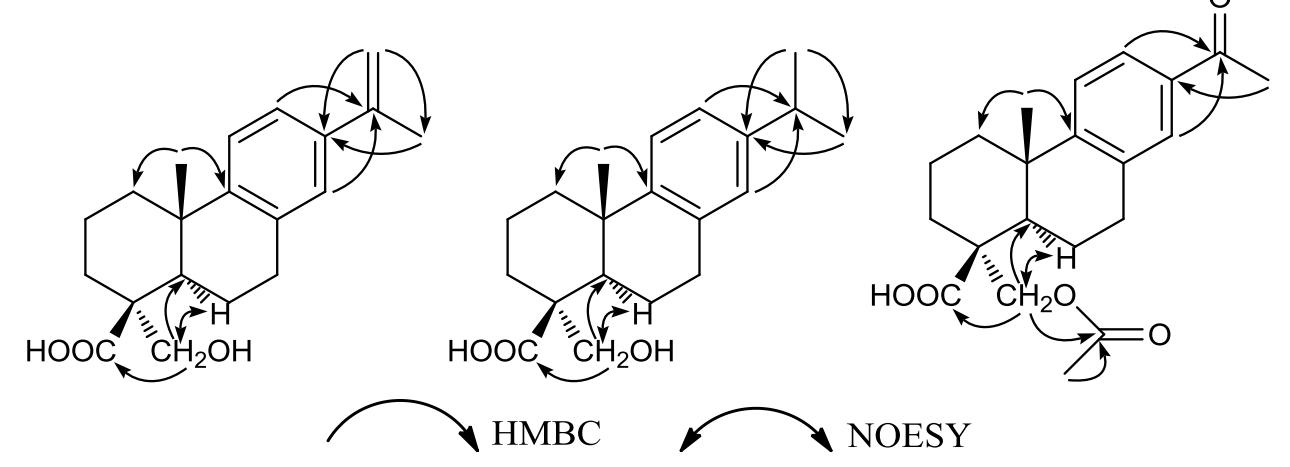

Figure 2. Key HMBC and NOESY correlations for compounds $\mathbf{1}$ to 3.

Callicapoic acid M5 (3), a white amorphous powder, possessed a molecular formula of $\mathrm{C}_{21} \mathrm{H}_{26} \mathrm{O}_{5}$ according to its HR-ESI-MS signal at $m / z 359.1873[\mathrm{M}+\mathrm{H}]^{+}$. The $1 \mathrm{D}$ (Table 1 ) and 2D NMR data of 3 clearly revealed the presence of an abietane-type diterpene skeleton, and also indicated its structure be similar to that of $\mathbf{1}$ except for the two side chains. The differences between them were that the isopropenyl was replaced by an acetyl at C-13, and the hydroxyl at C-18 was acetylated. The first difference had characteristic resonances at $\delta_{\mathrm{H}} 2.56(3 \mathrm{H}, \mathrm{s})$; and $\delta_{\mathrm{C}} 26.7,198.3$ which implied the presence of an acetyl, while HMBC correlations from protons of methyl at $\delta_{\mathrm{H}} 2.56$ to $C-13(\delta 134.8)$ suggested that 
acetyl was connected to $\mathrm{C}-13$. The second difference in the characteristic resonances at $\delta_{\mathrm{H}} 2.06(3 \mathrm{H}, \mathrm{s})$; and $\delta_{C} 20.9,171.0$ also implied the presence of an acetyl, HMBC correlations from the methylene protons at $\delta_{\mathrm{H}} 4.10$ and $4.49\left(\mathrm{H}_{2}-18\right)$ to $\mathrm{C}-21(\delta 171.0)$ suggested that the $\mathrm{C}-18$ hydroxyl was acetylated. The relative configuration of $10-\mathrm{CH}_{3}$ was established as $\beta$-oriented, $4-\mathrm{CH}_{2} \mathrm{O}$ - was confirmed to be $\alpha$-oriented by a NOESY experiment, the same as those of $\mathbf{1}$ and $\mathbf{2}$. Therefore, compound $\mathbf{3}$ was thus identified as 15-acetyl-19-carbethoxy-8,11,13-abietatetraen-18-oic acid (Figure 1).

Nitric oxide (NO) plays an important role in the inflammatory process [17].The inhibition of NO release may be effective as a therapeutic agent in the inflammatory diseases [18]. Therefore, compounds 1 to 3 were tested for the inhibitory activity against the production of NO in RAW 264.7 stimulated by lipopolysaccharide (LPS). The anti-inflammatory assay was carried out according to the procedure described previously. The results were summarized in Table 2 and indicated that all the three compounds could significantly inhibit NO introduction in LPS-activated RAW 264.7 macrophage cells.

Table 2. Anti-inflammatory effects of compounds 1-3 from Callicarpa macrophylla Vahl. on LPS-induced RAW264.7 macrophages.

\begin{tabular}{|c|c|c|c|}
\hline Compound & Conc. $(\mu \mathrm{M})$ & NO Inhibitory Rate (\%) & Cell Viability (\%) \\
\hline 1 & 50 & $37.89 \pm 3.28^{a}$ & $94.26 \pm 7.78$ \\
\hline 2 & 50 & $34.47 \pm 4.35^{\mathrm{a}}$ & $93.58 \pm 2.16$ \\
\hline 3 & 50 & $40.13 \pm 2.45^{\mathrm{a}}$ & $94.76 \pm 3.91$ \\
\hline$Z, Z^{\prime}-6,6^{\prime}, 7,3^{\prime} \alpha$-Diligustilide ${ }^{b}$ & 50 & $69.37 \pm 6.08^{a}$ & $108.50 \pm 1.90$ \\
\hline
\end{tabular}

${ }^{\mathrm{a}}$ The three compounds were tested in the same value as $50 \mu \mathrm{M} .{ }^{\mathrm{b}} p<0.01$, significantly different from LPS model group. Data were presented as mean $\pm \mathrm{SD}$ of three independent experiments.

\section{Experimental}

\subsection{General Procedures}

Optical rotations were determined on a $241 \mathrm{MC}$ polarimeter (Perkin-Elmer, Waltham, MA, USA). UV spectra were obtained on Perkin Elmer Lambda 35 UV/VIS Spectrometer. IR spectra were recorded on a IFS 55 spectrophotometer (Bruker, Billerica, MA, USA). The NMR data were recorded on a Bruker AV-600 spectrometer. The HR-ESI-MS data were obtained on a LCT Premier XE time-of-flying mass spectrometer (Waters, Milford, MA, USA). Chromatography was performed on silica gel (200-300 mesh; Qingdao Marine Chemical Group Co. Ltd., Qingdao, China) and ODS (30-50 $\mu \mathrm{m}$; Tianjin Mical Reagent Co., Tianjin, China). Prep. HPLC was performed on a system comprised of a L-7110 pump and a L-7420 UV spectrophotometric detector set at $203 \mathrm{~nm}$ (Hitachi, Tokyo, Japan). A YMC C 18 reversed-phase column $(5 \mu \mathrm{m}, 10 \times 250 \mathrm{~mm}$; flow rate $2.0 \mathrm{~mL} / \mathrm{min})$ was used.

\subsection{Plant Material}

Dried whole herb of Callicarpa macrophylla Vahl. were collected in Yunnan Province, China, in August 2011 and identified by Jincai Lu (School of Traditional Chinese Materia Medica, Shenyang Pharmaceutical University). A voucher specimen (No. 20110801) was deposited in the Research Department of Natural Medicine, Shenyang Pharmaceutical University.

\subsection{Exaction and Isolation}

Dried whole herb of Callicarpa macrophylla Vahl. $(4.5 \mathrm{~kg})$ was extracted with $50 \mathrm{~L} 95 \% \mathrm{EtOH}(\times 3)$ under reflux conditions for three hours to give a crude extract, which was suspended in $\mathrm{H}_{2} \mathrm{O}$ and successively extracted with petroleum ether (PE), $\mathrm{CHCl}_{3}$ and EtOAc to yield a PE-soluble fraction $(17.2 \mathrm{~g})$, a $\mathrm{CHCl}_{3}$-soluble fraction $(261.7 \mathrm{~g})$ and an EtOAc-soluble fraction $(55.3 \mathrm{~g})$. A part of the $\mathrm{CHCl}_{3}$-soluble fraction (70 g) was subjected to column chromatography (CC, silica gel, gradient of PE-acetone 100:1-0:100) to afford 46 fractions (numbered 1-46). Fractions 30-36 (5.2 g) were separated by CC (ODS, $\mathrm{MeCN}-\mathrm{H}_{2} \mathrm{O} 30: 70, \mathrm{MeCN}-\mathrm{H}_{2} \mathrm{O} 40: 60$ ) to yield fraction ods40, which was 
further subjected by semi-preparative reversed-phase $\mathrm{HPLC}\left(\mathrm{MeOH} / \mathrm{H}_{2} \mathrm{O}\right.$ with $0.2 \% \mathrm{HCO}_{2} \mathrm{H},(62: 38$, $v / v)$ as mobile phase, flow rate $3.0 \mathrm{~mL} / \mathrm{min}$, wavelength $203 \mathrm{~nm})$, to afford $\mathbf{1}(10.8 \mathrm{mg}), \mathbf{2}(16.4 \mathrm{mg})$ and $3(11.2 \mathrm{mg})$, respectively.

Callicapoic Acid M3 (1). White amorphous powder, $[\alpha]_{D}^{20}+57.0(\mathrm{MeOH}, c 0.37)$. UV (MeOH) $\lambda_{\max }: 211$, $250 \mathrm{~nm}$. IR (KBr) $v_{\max }\left(\mathrm{cm}^{-1}\right): 3401,2930,1700$ and $1561 .{ }^{1} \mathrm{H}-\mathrm{NMR}$ and ${ }^{13} \mathrm{C}-\mathrm{NMR}$ spectral data are shown in Table 1. HR-ESI-MS $m / z: 315.1958\left(\mathrm{C}_{20} \mathrm{H}_{27} \mathrm{O}_{3}{ }^{+}\right.$, $[\mathrm{M}+\mathrm{H}]^{+}$, calc. 315.1960).

Callicapoic Acid M4 (2). White amorphous powder, $[\alpha]_{D}^{20}+22.2(\mathrm{MeOH}, c 0.10)$. UV (MeOH) $\lambda_{\max }: 205$, $266 \mathrm{~nm}$. IR (KBr) $v_{\max }\left(\mathrm{cm}^{-1}\right): 3426,2923,1630$ and $1384 .{ }^{1} \mathrm{H}-\mathrm{NMR}$ and ${ }^{13} \mathrm{C}-\mathrm{NMR}$ spectral data are shown in Table 1. HR-ESI-MS $m / z: 339.1927\left(\mathrm{C}_{20} \mathrm{H}_{28} \mathrm{NaO}_{3}{ }^{+},[\mathrm{M}+\mathrm{Na}]^{+}\right.$, calc. 339.1936).

Callicapoic acid M5 (3). White amorphous powder, $[\alpha]_{D}^{20}+41.2(\mathrm{MeOH}, c 0.24)$. UV (MeOH) $\lambda_{\max }$ : 209 , $258 \mathrm{~nm}$. IR (KBr) $v_{\max }\left(\mathrm{cm}^{-1}\right): 3411,2927,1723,1658$ and $1351 .{ }^{1} \mathrm{H}$ - and ${ }^{13} \mathrm{C}-\mathrm{NMR}$ spectral data are shown in Table 1. HR-ESI-MS $m / z: 359.1873\left(\mathrm{C}_{21} \mathrm{H}_{27} \mathrm{O}_{5}{ }^{+},[\mathrm{M}+\mathrm{H}]^{+}\right.$, calc. 359.1858).

\subsection{Anti-Inflammatory Assay}

The anti-inflammatory activities of compounds 1 to 3 were evaluated using LPS-induced RAW 264.7 cells. RAW 264.7 macrophages cells $\left(8 \times 10^{4}\right.$ cells / well $)$ were suspended in $100 \mu \mathrm{L}$ of DMEM supplemented with $10 \%$ fetal bovine serum, and precultured in 96-well microplates and $5 \% \mathrm{CO}_{2}$ in air for $12 \mathrm{~h}$ at $37^{\circ} \mathrm{C}$, then test compounds $(50 \mu \mathrm{mol} / \mathrm{L})$ were cultured, and were treated with or without $1 \mu \mathrm{g} / \mathrm{mL}$ LPS for $24 \mathrm{~h}$. NO production in each well was assessed by measuring the accumulation of nitrite in the culture medium using Griess reagent. Cytotoxicity was determined by 3-(4,5-dimethyl-2-thiazolyl)-2,5-diphenyl-2H-tetrazolium bromide (MTT) colorimetric assay. Briefly, after $24 \mathrm{~h}$ incubation with test compounds, MTT $(20 \mu \mathrm{L}, 5 \mathrm{mg} / \mathrm{mL}$ in PBS) solution was added to the wells. After $4 \mathrm{~h}$ of culturing, the medium was removed and DMSO $100 \mu \mathrm{L} /$ well was then added to dissolve the formazan produced in the cells. The optical density of the formazan solution was measured with a microplate reader at $490 \mathrm{~nm}$. Z, Z, $-6,6^{\prime}, 7,3^{\prime} \alpha$-diligustilide was used as positive control. Each test compound was dissolved in dimethyl sulfoxide (DMSO), and the solution was added to the medium (final DMSO concentration was $0.1 \%$ ). MTT experiments were repeated three times. The NO inhibitory ratio $(\%)$ was calculated by the following formula:

$$
\text { NO inhibitory ratio }(\%)=\left(\mathrm{A}_{570, \text { LPS }}-\mathrm{A}_{570, \text { sample }}\right) / \mathrm{A}_{570, \mathrm{LPS}} \times 100
$$

Acknowledgments: This work was financially supported by Key Research Projects of Higher Education in Henan province (15A350007) and Doctoral Fund Project of Henan Polytechnic University (B2014-068). We thank for Zi-Shuang Liu of the Analysis \& Testing Center of Innotech Technology (Dalian) Co., Ltd. for the NMR data measurements. We also thank Professor Jincai Lu for identification of the plant material.

Author Contributions: Zhen-Hui Wang designed the experiments and wrote the paper; Chao Niu and De-Jun Zhou performed the experiments; Ji-Chuan Kong and Wen-Kui Zhang modified the paper. All authors read and approved the manuscript.

Conflicts of Interest: The authors declare no conflict of interest.

\section{References}

1. Liu, M.S. Introduction of Li Nationality Medicine; People's Medical Publishing House: Beijing, China, 2008; pp. 74-78.

2. Wang, Y.J.; Yang, Y.F.; Gao, D. Advances in studies on chemical constituents in plants of Callicarpa Linn. and their bioactivities. Chin. Tradit. Herb. Drugs 2008, 39, 133-138.

3. Dong, L.; Liu, M.S.; Wang, J.H. Lipophilic compounds of Callicarpa nudiflora Hook. Et Arn. Chin. J. Med. Chem. 2009, 19, 371-374.

4. Dong, L; Wang, J.H.; Liu, M.S. Phenolic acid constituents of leaves from Callicarpa nudiflora Hook. Et Arn. J. Shenyang Pharm. Univ. 2010, 27, 290. 
5. Cai, J.P.; Dong, L.; Guan, W.W.; Liu, M.S. Research progress of Callicarpa nudiflora. Drugs Clin. 2012, $27,60-63$.

6. Pan, P.; Sun, Q.S. The chemical composition of Callicarpa macrophylla Vahl. Et Arn. J. Shenyang Pharm. Univ. 2006, 23, 565-567.

7. Talapatra, S.K.; Polley, M.; Talapatra, B. Terpenoids and Related Compounds. Part 32. Calliphyllin, a New Diterpene from the Leaves of Callicarpa macrophylla. Cheminform 1995, 26, 40. [CrossRef]

8. Goel, M.K.; Kukreja, A.K.; Singh, A.K.; Khanuja, S.P.S. In vitro plant growth promoting activity of phyllocladane diterpenoids isolated from Callicarpa macrophylla Vahl. in shoot cultures of Rauwolfia serpentine. Nat. Prod. Commun. 2007, 2, 799-802.

9. Xu, J.; Li, S.; Sun, X.C.; Ma, J.; Liu, F.; Tong, L.; Lee, D.; Ohizumi, Y.; Tuerhong, M.; Guo, Y.Q. Diterpenoids from Callicarpa kwangtungensis and their NO inhibitory effects. Fitoterapia 2016, 113, 151-157. [CrossRef] [PubMed]

10. Zhang, L.; Dong, L.; Huang, J.; Liu, M.S.; Li, G.Y.; Zhang, C.; Zhang, K.; Wang, J.H. 3,4-seco-Labdane diterpenoids from the leaves of Callicarpa nudiflora and their inhibitory effects on nitric oxide production. Fitoterapia 2013, 83, 218-223. [CrossRef] [PubMed]

11. Lee, C.K.; Fang, J.M.; Cheng, Y.S. Abietanes from leaves of Juniperus chinensis. Phytochemistry 1994, 35, 983-986. [CrossRef]

12. Su, W.C.; Fang, J.M.; Cheng, Y.S. Diterpenoids from leaves of Cryptomeria japonica. Phytochemistry 1996, 41, 255-261.

13. Cambie, R.C.; Mathai, K.P. The structure of pododacric acid. Aust. J. Chem. 1971, 24, 1251-1256. [CrossRef]

14. Shishido, K.; Nakano, K.; Wariishi, N.; Tateishi, H.; Omodani, T.; Shibuya, M.; Goto, K.; Ono, Y.; Takaishi, Y. Tripterygium wilfordii var. regelii which are interleukin-1 inhibitors. Phytochemistry 1994, 35, 731-737.

15. Duan, H.Q.; Kawazoe, K.; Bando, M.; Kido, M.; Takaishi, Y. Di- and triterpenoids from Tripterygium hypoglaucum. Phytochemistry 1997, 46, 535-543. [CrossRef]

16. Shmidt, E.N.; Khan, V.A.; Isaeva, Z.A.; Drebushchak, T.D.; Dubovenko, Z.V.; Kemertelidze, E.P.; Pentegova, V.A. Terpenoids of the oleoresins of picea orientalis and abies normanniana growing in the Caucasus. Khimiya Prirodnykh Soedinenii 1982, 2, 189-194.

17. Calixto, J.B.; Otuki, M.F.; Santos, A.R. Anti-inflammatory compounds of plant origin. Part I. Action on arachidonic acid pathway, nitric oxide and nuclear factor kB (NF-kB). Planta Med. 2003, 69, 973-983. [PubMed]

18. Lee, H.J.; Kin, N.Y.; Jang, M.K.; Son, H.J.; Kim, K.M.; Sohn, D.H.; Ryu, J.H. A sesquiterpene, dehydrocostus lactone, inhibits the expression of inducible nitric oxide synthase and TNF- $\alpha$ in LPS-activated macrophages. Planta Med. 1999, 65, 104-108. [CrossRef] [PubMed]

Sample Availability: Samples of the compounds are available from the authors.

(C) 2017 by the authors. Licensee MDPI, Basel, Switzerland. This article is an open access article distributed under the terms and conditions of the Creative Commons Attribution (CC BY) license (http:/ / creativecommons.org/licenses/by/4.0/). 